\title{
The Effect of a Task-Based, Curriculum-Enrichment Program for Vocabulary Learning Strategies on Saudi University Students
}

\author{
Ibtesam Mohammed Al-Yahya \\ Imam Muhammad bin Saud Islamic University \\ Riyadh, Saudi Arabia \\ E-mail: imyahya@imamu.edu.sa
}

\begin{abstract}
Received: September 14, $2021 \quad$ Accepted: October 7, $2021 \quad$ Published: October 20, 2021
doi:10.5296/ijl.v13i5.19112

URL: https://doi.org/10.5296/ijl.v13i5.19112
\end{abstract}

\begin{abstract}
The current study set to investigate the effect of introducing particular vocabulary learning strategies (VLSs) to Saudi, female students. The strategies implemented were six: 'grouping words together to study them' (GW); 'putting English labels on physical objects' (LO); 'using scales for gradable words'(SC); 'using semantic maps'(SM); 'using the keyword method' (KW) and 'studying words with a pictorial representation of their meaning' (PR). The participants were a group of 90 level-one students studying in the Department of English Language and Translation at Imam Muhammad Ibn Saud Islamic University, Riyadh. They were assigned to two groups: control $(\mathrm{N}=44)$ and experimental $(\mathrm{N}=46)$; only the experimental group received instructions on those strategies in a form of task-based, curriculum-enrichment materials. To assess the effectiveness of such a VLS instruction (VLSI) program, three areas were examined: the students' vocabulary learning (VL), the frequency of strategy-use, and their VLS repertoire. The data of the study were derived from three instruments: pre-post vocabulary achievement test (VAT), pre-post questionnaire and semi-structured interviews. The analysis of the data revealed the effectiveness of the VSBI program in the areas identified above. First, it improved the students' vocabulary achievement as well as their VL, in general. Second, it increased the frequency of using general categories of VLSs (i.e. VLSs altogether, consolidation strategies, metacognitive strategies). It also increased the frequency of using five of the taught strategies which were GW, LO, SC, KW, and PR. Third, the VSBI program proved to be positive in that it changed and improved the students' VLS repertoire.
\end{abstract}

Keywords: Vocabulary learning strategies, Vocabulary strategy instruction, Vocabulary learning, Vocabulary achievement 


\section{Introduction}

In theoretical and empirical second language acquisition (SLA) research, the essential role that lexis plays in SL learning and teaching has been repeatedly acknowledged. More specifically, the importance of VL is perceived from a linguistic perspective (Cruse, 2000) as well as from a usage perspective (Politzer, 1978). The importance of vocabulary can be explained in McCarthy's statement: "No matter how well the student learns grammar, no matter how successfully the sounds of L2 [SL] are mastered, without words to express a wide range of meanings, communication in an L2 just cannot happen in any meaningful ways" (1990, p.iix). In language learning, the importance of vocabulary is seen in all the four skills: speaking, listening, reading and writing; Smith (1998) asserted that having large and rich vocabulary helps learners develop their listening, reading, speaking, writing, and thinking abilities. Other researchers have gone even further and proposed that vocabulary can help in fostering language fluency. For example, Koizumi (2005) concluded that a strong correlation does exist between size and depth of the active vocabulary, on the one hand, and the speed of speech, on the other hand.

The dominant role that vocabulary plays in learning and understanding language as well as in communicating with others in social life made researchers think of ways to help language learners develop this important aspect. According to researchers, vocabulary learning strategies (VLSs) play a key role; they may help learners discover the meaning of a new word and consolidate a word previously encountered. (Cohen, 1996; Nation, 2001; Schmitt, 1997) Nevertheless, such strategies are often not adopted automatically (Cameron, 2001), are poorly used or even neglected (Nation, 2001). Hence, it has been frequently suggested that apart from teaching specific words, teachers should aim at equipping learners with strategies for expanding their vocabulary knowledge. (e.g. Hedge, 2000; Hulstjin, 1992).

The need for such strategies is of paramount importance specially in English as a foreign language (EFL) contexts, such as Saudi Arabia, where students do not have much exposure to the target language. Therefore, teaching in a foreign language context which is mostly viewed as being teacher-centered, the researcher has thought of teaching such strategies and then investigating whether they are beneficial for FL learners. Unfortunately, most English teachers in Saudi Arabia do not focus on such strategies, instead they focus on giving students information as far as the language content is concerned. At the same time, the majority of university students prefer to depend on their teachers throughout the process of learning and do not make any effort to develop themselves. Therefore, most students do not develop rich vocabulary that enables them to communicate freely and appropriately in English.

\section{Literature Review}

\subsection{Vocabulary Learning (VL)}

Earlier, vocabulary was neglected in both SLA research as well as teaching methodologies despite its great importance. In this regard, Zimmerman (1997) emphasized that most language teaching methods have generally paid little attention to teaching vocabulary throughout the history of SLA. However, interest in vocabulary has gradually aroused; it has 
drawn researchers' interest within the mainstream of SLA since the late 1980s (Nation, 1997) and particularly the 1990s (Sanchez\& Manchon, 2007). With the explosion of such studies, a central focus of scholarly investigations has been devoted to the concept of vocabulary learning strategies.

\subsection{Vocabulary Learning Strategies (VLSs)}

There is not a precise definition of VLSs that is agreed upon. For example, Schmitt (1997) provided a broad definition based on Rubin's (1987) definition of learning " i.e. the process by which information is obtained, stored, retrieved and used", and hence for him VLSs are "anything which affect this broadly defined process" (Schmitt, 1997, p.203). A more detailed definition of VLSs was provided by other researchers such as Sökmen who defined such strategies as: "actions made by the learner in order to help them to understand the meaning of a word, learn them and remember them later" (1997, p. 237).

VLSs have been classified by different second and foreign language researchers such as Gu and Johnson (1996), Schmitt (1997), and Nation (2001). Of the three typologies, Schmitt's has additional advantages and hence the researcher chose it as a reference for the VLSs classification of the study; it is a taxonomy that succeeds to clearly and precisely provide defined VLS categories.

Apart from the descriptive nature of most research in the area of VLSs, other studies reported certain positive outcomes of using such strategies; a sort of correlation has been recorded between VLS use, on the one hand, and vocabulary learning (Zheng, 2010), vocabulary size (Kafiapour et al, 2011) and vocabulary achievement (Ningjue, 2011; Al-Fuhaid, 2004), on the other hand. Based on the abovementioned positive outcomes of strategy use as well as the fact the many learners do not develop sufficient mastery of a strategy repertoire on their own (Cohen, 1996), many researchers suggested the need for vocabulary learning strategy instruction (e.g. Al-Fuhaid, 2004; Lawson \& Hogben, 1996; Sanaoui, 1995; Schmitt, 1997).

\subsection{Vocabulary Strategy-Based Instruction (VSBI)}

Research into vocabulary teaching has suggested that it should not consist of merely teaching specific words, rather it should also include VSBI; that is equipping learners with strategies for expanding their vocabulary knowledge (Hedge, 2000; Hulstjin, 1992). However, such strategies were recorded to have been poorly used (Al-Fuhaid, 2004) or neglected by learners (Nation, 2001) or that only basic ones were found to have been exclusively used by most learners (Schmitt, 1997). Hence, instructing learners to use a wide range of VLSs is absolutely needed.

Since the importance of instruction on VLSs is widely recognized and acknowledged, a number of intervention studies have been conducted. The purpose of most research has been experimental in nature; the effectiveness of one or multiple strategy (ies) is investigated against another/ other strategy (ies) (e.g. Atay \& Ozbulgan, 2007; Rasekh \& Ranjbary, 2003; Tavakoli \& Gerami, 2013) or against traditional vocabulary teaching. (e.g. Chen \& Hsiao, 2010; Heidari, Karimi \& Imani, 2012; Mizumoto \& Takeuchi, 2009; Nemati, 2009, 2013; Sardroud, 2013) 
Of such intervention studies, the proposed frameworks were mostly based on CALLA model (e.g. Tassana-ngam, 2005; Bornay, 2011; Sardroud, 2013; Mizumoto \& Takeuchi, 2009). This model provides direct instructions on strategies in the form of five stages in a recursive fashion; strategies are introduced, taught, practiced, evaluated, and finally applied and the degree of explicitness decreases as strategies change from being declarative knowledge into procedural knowledge. However, as new strategies or new usages are added to students' strategic repertoire, the degree of explicitness increases and the cycle repeats again. Such a model separates rather than integrates SBI and language-based instruction and there is no need for separating them since strategies are meant in the first place to help learners with their language. Moreover, such a model with its five phases is time-consuming making most teachers avoid it. Furthermore, those intervention studies were mostly conducted in Iran (Nemati, 2013; Marefat \& Shirazi, 2003; Tavakoli \& Gerami, 2013) and other south eastern Asia (Tassana-ngam, 2005, Chen \& Hsiao, 2010; Mizumoto \& Takeuchi, 2009; Nemati, 2009).

To the best of the researcher's knowledge, the only intervention study that dealt with Saudi participants was conducted by Alseweed (2000); those participants were EFL male undergraduate learners. In order to fill in the gap, the researcher aimed at investigating the effect of training EFL Saudi, female, undergraduate learners on the use of a number of VLSs. In order to ensure the effectiveness of such training, those strategies were elicited from a need analysis questionnaire. Additionally, the framework for training is a task-based, curriculum enrichment program so as to integrate both SBI and language-based instruction and at the same time save time; the students at the end of each class would practice a specific strategy through working on a 10-minute task.

\section{Method}

\subsection{Design of the Study}

The researcher followed the quasi-experimental method in investigating the effect of a program for VLSI on university students. More specifically, the independent variable was the proposed program based on six strategies whereas the dependant variables were three; they were all related to the effect of the program on students in terms of their VL, the frequency of their VLSs, and their overall VLS repertoire. The design employed two groups: a control group and an experimental one; each of which was taught a reading course by the same instructor utilizing the same text book. However, only the experimental group received strategic instruction in a form of curriculum-enrichment materials which were modular and task- based.

\subsection{Participants}

The participants were a group of 90 level-one students studying in the Department of English Language and Translation at Imam Mohammed Ibn Saud Islamic University(IMSIU), Riyadh, Saudi Arabia. The participants constituted a homogeneous group; they were females and native speakers of Arabic, and they roughly belonged to the same age category (19-20). Additionally, they had all studied English for six years in intermediate and secondary schools 
in Saudi Arabia. These students came from two classes of which one was assigned as the control group ( $\mathrm{N}=44)$ whereas the other as the experimental group $(\mathrm{N}=46)$. The participants in both groups took a (pre-post) questionnaire as well as a (pre-post) vocabulary achievement test (VAT), however, only 10 students from the experimental group voluntarily participated in the interview.

\subsection{Instruments}

Based on the purpose of the study, the research questions, and the resources and time available, a mixed-approach was adopted. This methodological design could serve for triangulation seeking convergence, corroboration and correspondence of results across different methods. (Greene, 2001, p.253) In the current study, the triangulation was achieved by the adoption of both quantitative (the questionnaire and the test) and qualitative methods (interviews). Of the three data collection methods, the pre-post questionnaire and the pre-post VAT were conducted almost simultaneously whereas the interviews began only later after the strategy instructions had finished.

\subsubsection{Questionnaire}

The researcher had reasonable grounds for choosing this quantitative method: first, the review of related literature uncovered that it was widely employed and yielded valid results; second, this instrument was appropriate as it was based on the resources and time available, and it could serve the researcher in finding out answers for the research questions.

The items were basically adapted from Schmitt's taxonomy of VLSs (1997) as well as that of Al-Fuhaid (2004) taking into account what might fit for the participants of the study based on the researcher's goals, experience and findings of the related literature in the Saudi context (e.g. Alseweed,1996, 2000, 2005; Al-Fuhaid, 2004, Hamouda, 2013; Al-Haysony, 2011; Alhaisoni, 2014).

The questionnaire was made up of 49 close-ended items requiring a frequency of use indication for the strategy in question from the predefined range: 'frequently', 'sometimes' and 'never' (see Appendix 1). The questionnaire was used to explore the frequency of vocabulary learning strategies the students report using in coping with unknown words (section 1), consolidating the meaning of learned words (section 2), and improving their English vocabulary knowledge and/ or learning new words on their own (section 3). It was administrated to the two groups (control and experimental) at the very beginning of the course and then again at the very end of the course so as to trace any changes, if any, in the frequencies of the VLSs students employ, their overall VLS repertoire and their vocabulary knowledge as a result of the type of instructions they received in their reading course.

\subsubsection{Vocabulary Achievement Test (VAT)}

An achievement test is a test which aims at measuring students' mastery of what has been taught. As such, it is concerned with a representative sample of a syllabus or a course book. (Heaton, 1988) Therefore, the researcher considered this type of test as the most suitable one to test the effectiveness of the program; the experimental group might surpass their control 
counterparts in a general vocabulary test simply because they have been exposed to extra vocabulary items, however, in an achievement test they can only surpass the control group due to their own way of studying the vocabulary items and the relative program might play a role in this respect. The VAT (see Appendix 2) composed was used as a pre test to measure the students' vocabulary knowledge before being exposed to the vocabulary items in the prescribed book. The same VAT was also used as a post test so as to measure their vocabulary achievement uncovering the progress both groups have made and hence the overall effectiveness of the program.

\subsubsection{Semi-Structured Interview}

A semi-structured interview was adopted in this study since it has been proven to be flexible and hence be popular in qualitative designs (Nunan, 1992). On the one hand, Merriam (1998) affirmed that such a type enables the researcher to respond to new or even unforeseen ideas regarding the topic at hand. On the other hand, Nunan (ibid) indicated that the interviewees can develop ideas and speak at length regarding the issues raised by the interviewer.

Two main issues were addressed in the interviews: those in the questionnaire (VLS use) as well as those in relation to the VLSI program. The interview questions were eight (see Appendix 3) and were classified into three parts: part 1 concerned the students' use of the six VLSs they were trained in (questions: 1-2); part 2 probed into the outcome of the VLSI program on the participants (questions: 3-4-5-6-7); and part 3 looked at the students' suggestions on how to improve the VLSI program offered (question 8). The interviews were held with 10 participants from the experimental group. However, to make this sample representative, the participants chosen belonged to different levels: high (3), average (4), and low (3); the participants' classification was based on their scores in the pre-test (VAT).

\subsection{Vocabulary Learning Strategy Instruction}

\subsubsection{Principles}

The program developed for teaching the selected VLSs was based on certain principles. First, it focused on promoting learner autonomy and hence making VL more learner-centered than teacher-centered. Second, the program was a modular one; a self contained unit in which each task, though separate, led to the other one for they all aimed at teaching a specific type of consolidation strategies: grouping words together to study them; putting English labels on physical objects; using scales for gradable words; using semantic maps; using the keyword method and studying words with a pictorial representation of their meaning. Third, the program was task-based; it was made up of 12 ten-minute tasks to be completed in class along with 12 follow-up tasks to be completed at home. On the one hand, a task, unlike a drill or an exercise, provided a meaningful context for the students to practice the target language; a task is "An activity which requires learners to arrive at an outcome from given information through some process of thought....." (Prabhu ,1987, p.24). On the other hand, a 10- minute task introduced the students to the strategies without adding much to the teaching or studying load. Finally, the program functioned as curriculum-enrichment materials; it could be easily integrated with the reading course the researcher was teaching, just as with any other skill 
course. In order to make the program more meaningful to the students, the materials were integrated with the textbook; the vocabulary items included in each task were chosen to match the topic of the relevant chapter.

\subsubsection{Construction}

In an attempt to make the program beneficial, the choice of the strategies to be taught was based on a need-analysis questionnaire. To put it in other words, the researcher decided to teach the strategies that were reported to have been rarely, if ever, used by a similar sample so as to ensure that the students learn something new to them and hence find the program for VLSI more beneficial. After deriving the strategies to be taught, the researcher set to build the program itself taking into account the underlying principles mentioned earlier. Since the program was meant to be integrated with the reading course, the order of the tasks was based on the topics raised in each unit in the textbook. It was set that each unit was to be discussed in two consecutive weeks making up 12 training sessions on VLSs. Since only one strategy was introduced each week, the researcher chose to recycle the strategies afterwards and hence helped the students explore such strategies further.

Taken into account the topic of the unit, on the one hand, and the best way through which a specific strategy can be best practiced meaningfully, on the other hand, the 12 tasks were formulated. Attached with each task was a brief explanation for the relevant strategy provided in Arabic so as to ensure that students could successfully employ it. Additionally, examples of English words were provided to further clarify how this strategy could be used.

\section{Data Analysis}

The quantitative and qualitative data gathered were analyzed in detail in order to find answers for the main research questions. As for the quantitative data, the scores achieved by the experimental group in the pre-post tests as well as those achieved by their control counterparts were statistically compared so as to measure how much improvement each group had made. The test scores were analyzed using SPSS to find out whether the VLSI program had any effect on the vocabulary achievement of the experimental group; t-test and ANCOVA were used to examine whether the difference between the mean scores in the pre-post tests of the experimental group was greater than that of the control group.

Similarly, the results obtained from the experimental group in the pre-post questionnaires as well as those achieved by their control counterparts were statistically compared so as to trace any changes in the students' VLS use. The results obtained were analyzed using SPSS to find out whether the VLSI program had any effect on the VL of the experimental group, their VLS repertoire, and the frequency of VLSs, in general, and that of the six strategies introduced, in particular. To obtain the results, t-test was used so as to examine whether the difference between the mean scores in the use of the VLSs altogether, the use of each of the three dimensions (discovery- consolidation- metacognitive) altogether, and the use of each of the six strategies in the pre-post questionnaires of the experimental group was greater than that of the control group.

As for the qualitative data, the responses taken from the semi-structured interviews were 
translated from Arabic into English and then analyzed appropriately. The responses obtained from yes/ no questions were expressed in percentages. As for the responses to the questions requiring a definite degree on a scale, the value was presented in relation to each participant. As for the rest of the responses, they were classified into themes and sub-themes in relation to each of the three research questions. Whenever possible, the qualitative data were used to check the consistency in the students' responses obtained from the other two instruments.

\section{Results and Discussion}

\subsection{First Research Question: Does VLSI Have Any Effect on the Students' VL?}

\subsubsection{Students' Vocabulary Achievement}

The results proved the first hypothesis which states that; "The proposed program for VLSI has a positive effect on the students' VL in general and the students' vocabulary achievement in particular." Such results are consistent with Oxford et al's (1990) conclusion that "Strategy training can enhance both the process of language learning and the product of language learning." (p.210).

Using ANCOVA as well as t-test for independent samples, the results of the (pre-post) VAT revealed that the difference was highly significant $[\mathrm{p}=.000]$ between the performance of the experimental group in the post VAT and that of the control group. And of the two groups, the experimental group [ $\mathrm{M}=21.415]$ outperformed the control group $[\mathrm{M}=15.125]$ in the post VAT although the control group $[\mathrm{M}=10.98]$ outperformed their experimental counterparts $[\mathrm{M}=$ 8.64] in the pre VAT. Therefore, it is very possible that the use of VLSs was behind the outperformance of the experimental group in the VAT. In fact, such a positive correlation between VLS use, on the one hand, and vocabulary achievement, on the other hand, is not new; it has already been recorded in previous literature (Ningjue, 2011; Al-Fuhaid, 2004).

\subsubsection{Students' Process of Vocabulary Learning}

Again, the results of the other two instruments (questionnaire and interviews) proved the first hypothesis. In general, the use of the metacognitive strategies by the experimental group increased as a result of being introduced to the VLSI program. Since such strategies help learners control and assess their learning, the increase in their use might reflect signs of improvement in the process of VL; such results are consistent with Llinares et al.'s findings (2008) regarding the effect of memory SI on improving students' VL, and those of Bornay's (2011) regarding the role of VSBI in developing the students' metacognitive awareness and their regulatory skills.

More specifically, of the 17 items, the difference was statistically significant for seven items; the students' use of all of these strategies increased. As for the first five strategies, they might all reflect measures of students' autonomy/ independence in their VL: the students decide the words that are important for them to learn, they form their own notebook for vocabulary, they plan revision, they evaluate their vocabulary knowledge instead of depending on their teachers, and they try out new strategies instead of just depending on specific familiar strategies. Such results are consistent with previous research regarding the positive impact of 
VLSI on students' autonomy/independence (Dörnyei, 2005; Little, 1997). They also corroborate Atay and Ozbulgan's (2007) as well as Heidari et al.'s (2012) findings on the role of VSBI in helping the participants to self-diagnose their learning difficulties, self-evaluate their performance, and experiment with familiar and unfamiliar strategies.

The last two strategies were related to the style of using VLSs. Firstly, the participants after the VLSI program have started to use many strategies in combination rather than using merely single strategies; a finding arrived at in previous research (Tassana-ngam, 2005). Secondly, the participants in the current study have started to select the most appropriate strategy for each word rather than using a fixed set of strategies for all words. The increase in the use of these two strategies revealed an increase in the students' knowledge of VLSs. Therefore, such findings are in line with those of Atay and Ozbulgan's (2007) regarding the effect of VSBI on increasing the knowledge of how and when to use these strategies as well as those of Rubin et al.'s (2007) concerning the impact of instructing students on the increase of their strategy knowledge.

The above mentioned results of the questionnaire were also consistent with the findings reported in the interviews. It was obvious that the participants benefited from the instructions they received in two main respects: their style of using VLSs and their VL. First, more than half of the students $(60 \%)$ confirmed having the courage and motivation to try out new VLSs on their own ; such enthusiasm is not surprising since some researchers (Heidari et al., 2012; Mizumoto \& Takeuchi, 2009) also found that VSBI can help in increasing the students' motivation in learning English.

Second, all participants revealed having a positive impact of the program on their selectivity in using VLSs. For instance, the participants no longer depended on a single strategy; rather they all started to use not less than three strategies though not necessarily in combination. Furthermore, some students $(60 \%)$ stated that they replaced the old strategies with some of the six VLSs introduced; other students (20\%) stated that they added some of the six VLSs introduced to their previously used ones, and still other students $(20 \%)$ stated that they used some of the six VLSs introduced in combination with their already preferred strategies.

Third, most participants (90\%) revealed that their motivation to plan revision for vocabulary increased. Interestingly, the participants, whose motivation for revision increased, justified this by two main reasons. Most of them (80\%) clarified that the usefulness of the introduced VLSs have made their revision result in better retention; a conclusion already reported in previous research (Chen \& Hsiao, 2010; Hsu, 2007; Sardroud, 2013). The other reason was related to how studying vocabulary became no longer a boring process but rather an interesting and easy one.

Fourth, the participants confirmed that the training program contributed to the improvement of their VL in four main issues: independence/autonomy, knowledge about VLSs, use of VLSs, and process of VL. Such findings were supported in previous research (Llinares et al., 2008; Zheng, 2010) as there was a positive correlation recorded between VL, on the one hand, and VLS use, on the other hand. 
5.2 Second Research Question: Does VLSI Affect the Frequency of the VLSs Used by the Students?

\subsubsection{Frequency of the VLSs Altogether}

The results from the pre-post questionnaire proved the second hypothesis which states that; "The proposed program for VLS instruction increases the frequency of the VLSs used by the students." First, a significant increase occurred for the experimental group in the use of the VLSs altogether; such results match what was found in previous research; Marefat and Shirazi (2003) as well as Mizumoto and Takeuchi (2009) found that the frequency of strategy use had altogether increased as a result of VSBI. This could be partly explained by Atay and Ozbulgan's findings (2007) regarding the effect of VLSI on increasing the knowledge of how and when to use such strategies. The increase in the frequency of VLSs altogether might also be ascribed to the usefulness of the VLSs introduced in the training program.

Additionally, the students benefited from the instructions they received regarding the metacognitive and consolidation strategies in general; their use of these two dimensions increased. As for the metacognitive dimension, the increase of its use can be justified by the development in the students' metacognitive awareness as well as their regulatory skills as a result of the VSBI they received; a finding arrived at in previous research (e.g. Bornay, 2011). And as for the consolidation dimension to which all taught strategies belonged, the increase of its use can explained by Chen and Hsiao's (2010) and Tavakoli and Gerami's (2013) findings regarding the role of VSBI in improving students' memory strategy use.

\subsubsection{Frequency of the Six VLSs}

The analysis of the questionnaires and interviews proved an increase in the use of five of the taught strategies. As for the questionnaire, the difference was insignificant only for one strategy which is SM, but it was highly significant for the other five strategies: LO [ $\mathrm{t}=$ $-10.592, \mathrm{p}=.000], \mathrm{PR}[\mathrm{t}=-11.379, \mathrm{p}=.000], \mathrm{SC}[\mathrm{t}=-14.413, \mathrm{p}=.000], \mathrm{GW}[\mathrm{t}=-4.074$, $\mathrm{p}=.000]$, and $\mathrm{KW}[\mathrm{t}=-19.571, \mathrm{p}=.000]$. Such results are in line with previous research such as Alseweed's (2000) study that found that VSI was beneficial in increasing the strategy use of learners.

As for the single strategy that did not change, the students' resistance to the use of SM can be explained in two ways. Firstly, it was reported in the interviews that this strategy was not used by seven participants $(70 \%)$ due to three features: time-consuming nature $(30 \%)$, difficult and complex nature (20\%), and confusing nature (20\%). Secondly, there were some justifications provided in previous research for the low use of similar strategies. For example, Al-Fuhaid (2004) found that his Saudi students preferred to use those strategies which are less cognitively demanding; not those which involve elaboration and active mental processing. In the same vein, Schmitt (1997) found that rote learning strategies were used most often whereas those which are cognitively-demanding were less commonly used. 
5.3 Third Research Question: Does VLSI Have Any Effect on the Students' Strategy Repertoire?

\subsubsection{Discovery Strategies}

Of the 10 strategies, the difference was statistically significant only for four strategies. More specifically, the students' use of the fourth strategy- i.e. using an English-English dictionaryincreased whereas their use of the other three strategies- i.e. 'asking teachers for Arabic translation', 'asking teachers for paraphrase or synonym of new words', and 'asking teachers for sentence including the new words'- decreased.

As for the single strategy which increased, it might imply a sort of improvement occurring in the students' VL; the students started to more frequently consult English-English dictionaries instead of merely using Arabic-English dictionaries. Concerning the decrease in the use of the other three strategies, it can be ascribed to the students' tendency to depend on themselves instead of asking teachers for help. After being introduced to the VSBI program, the students tended to appeal for help less frequently. This positive impact of VLSI on students' autonomy/ independence is consistent with previous research. (Dörnyei, 2005; Little, 1997)

\subsubsection{Consolidation Strategies}

Of the 22 strategies, the difference was statistically significant only for 12 strategies. More specifically, the students' use of two strategies- i.e. verbal repetition and written repetitiondecreased. However, their use of the other 10 strategies- i.e., LO, PR, SC, GW, KW, 'taking notes', 'associating the word with its coordinates', 'testing oneself with wordlists', 'continuing to study words over time', and 'interacting with classmates in English' - increased.

The changes in the frequency of using the above mentioned strategies can be linked to the sort of improvement that took place in the students' consolidation strategy use as a result of the VSBI program they received. For example, the decrease in the use of two strategies- i.e. verbal repetition and written repetition- can be ascribed to the students' tendency to use mechanical strategies less frequently. A plausible explanation for the decrease in the use of such strategies is that the students must have recognized that their retention improves when using other strategies which are more demanding. This is actually grounded in the Depth of Processing Hypothesis according to which that deeper analysis of a stimulus results in a better long-term retention (Graik \& Lockart, 1972).

Concerning the increase in the taught strategies: LO, PR, SC, GW, and KW; it can be justified on two grounds. On the one hand, the increase is inevitable since they were trained in these five strategies; a finding already reported in previous research (Chen \& Hsiao, 2010; Tavakoli \& Gerami, 2013). On the other hand, the students must have benefited from using such strategies in improving their vocabulary retention and hence started to use them more frequently.

Moving to the other five strategies whose use also increased, it can be postulated that the students were trying to exert effort to self-direct and improve their VL on their own; the impact of VSBI in promoting students' autonomy/independence is consistent with previous 
research (Dörnyei, 2005; Little, 1997).

\subsubsection{Metacognitive Strategies}

Of the 17 strategies, the difference was statistically significant only for seven strategies. The use of these strategies increased and this may reflect measures of students' autonomy/ independence in their VL. Hence, the increase in such strategies resembles what other researchers (Dörnyei, 2005; Little, 1997) found concerning the positive impact of VLSI on students' autonomy/independence. They also corroborated Atay and Ozbulgan's (2007) as well as Heidari et al.'s (2012) findings regarding the role of VSBI in helping the participants to self-diagnose their learning difficulties, self-evaluate their performance, and experiment with familiar and unfamiliar strategies.

\section{Conclusion}

The findings obtained from the quantitative and qualitative data proved having a positive impact of the VLSI program on the students' vocabulary achievement and VL, the frequency of VLS use, and the repertoire of VLSs. More specifically, the proposed program had a positive effect on the students' vocabulary achievement; the experimental group outperformed the control group in the post-test although the control group outperformed their experimental counterparts in the pre-test.

Additionally, the relevant program considerably improved the students' VL. For example, the students benefited from the instructions they received in their selectivity when using VLSs. Furthermore, there was a significant increase in the use of the metacognitive VLSs altogether and since such strategies help learners control and assess their learning, the increase in their use might reflect signs of improvement in the process of their VL.

There was also a significant increase in the use of the VLSs altogether as well as the use of individual strategies within each of the three dimensions (discovery-consolidationmetacognitive); such changes might reflect improvement in their process of VL as well as changes in their style of using VLSs. Lastly, the VLSI program brought about some changes in the students' strategy repertoire which could imply a sort of improvement in the participants' VLS use.

Based on such positive effects, the researcher can offer a set of recommendations: incorporating brief tasks that introduce VLSI in English textbooks, offering courses for in-service English teachers on LLSs, in general, and VLSs, in particular, and initiating courses and workshops for language learners as well as English teachers on LLSs and autonomous learning.

To conclude, the current study can be expanded regarding the following areas. Firstly, the researcher made use of a triangulated approach utilizing a questionnaire, a VAT and a semi-structured interview; however, incorporating the think-aloud technique might elicit more about the students' VLS use. More specifically, such an instrument may justify the significant differences in the VLS use particularly regarding the discovery dimension since no questions in the designed interview addressed the use of the strategies belonging to this 
particular dimension.

Secondly, the researcher investigated the impact of a VLSI program that incorporated six strategies belonging to the consolidation dimension, hence, other intervention studies in the Saudi context incorporating strategies from all the three dimensions (discoveryconsolidation- metacognitive) should be conducted to compare their results with those of the current research.

Thirdly, the researcher investigated the impact of VLSI on the students' VL, hence, other intervention studies in the Saudi context adopting the same instructional model should address other language skills (listening- speaking- reading- writing) so as to provide more insights into the relevant program.

Fourthly, the VLSI program implemented in this study integrated SBI and language instruction, however, there was no integration whatsoever to style based instruction though such instructions might bring about impressive results. In this respect, Cohen (2003) mentioned that one of the most important considerations in the design of a SBI is the incorporation of student's needs, and paying attention to learner's preferred learning styles can be an essential way for addressing students' needs. To find out the real benefits of such integration, other intervention studies incorporating styles into SBI can be carried out so as to compare their findings with those of the current study.

Fifthly, the VLSI program was implemented in a conventional classroom setting though a number of researchers indicated the crucial importance of SI for distance learners in particular (e.g. Zahedi, 2008). Hence, implementing the same instructional model in a blended educational setting, where students are allowed to interact with their classmates in conventional as well as online settings, might bring about results that can be compared with those of this study.

Finally, it was beyond the scope of this research project to attend to any particular individual learner difference variables such as gender and language proficiency. Such variables were addressed in previous intervention studies such as Sardroud (2013), Alseweed (2000), and Nemati (2013). Therefore, investigating such variables in other intervention studies, that are built on the same principles of the VLSI program proposed in the current study, might provide more insights into the effectiveness of the relevant program.

\section{References}

Al-Fuhaid, M. (2004). Vocabulary learning strategies: An empirical study of their use and evaluation by Saudi EFL learners majoring in English. Unpublished phD thesis, University of Durham.

Alhaisoni, E. (2014, January). Dictionary use strategies of Saudi EFL students across educational level and university major. International Journal of English and Education, 3(1), 250-277.

Al-Haysony, M. (2011). Dictionary look-up behavior of Saudi female EFL students. European Journal of Social Sciences, 26, 250-276. 


\section{Macrothink}

International Journal of Linguistics

ISSN 1948-5425

2021, Vol. 13, No. 5

Alseweed, M. (1996). Saudi students' word-solving strategies in reading in English. Unpublished master dissertation, Department of Languages and Linguistics, University of Essex.

Alseweed, M. (2000). The effects of proficiency and training on the word-solving strategies of Arab EFL readers. Unpublished PhD thesis, Department of Languages and Linguistics, University of Essex.

Alseweed, M. (2005). Overcoming unknown words. Journal of Educational and psychological sciences, 6(1), 5-37.

Atay, D., \& Ozbulgan, C. (2007). Memory strategy instruction, contextual learning and ESP vocabulary recall. English for Specific Purposes, 26, 39-51.

Bornay, N. (2011, December). Explicit strategy training in vocabulary learning for beginning Spanish students. Flinders University Languages Group Online Review, 4(3), 18- 31.

Cameron, L. (2001). Teaching language to young learners. Cambridge: Cambridge University Press.

Chen, I., \& Hsiao, H. (2010). The effect of keyword method on ESP vocabulary learning. Journal of Applied Linguistics, 3, 1-21.

Cohen, A. (1996). Second language use and strategies: Clarifying the issues. CARLA Working Paper Series\#3. Minnneapolis: University of Minnesota, Center for Advanced Research on Language Acquisition.

Cohen, A. (2003). The learner's side of foreign language learning: Where do styles, strategies, and tasks meet?. International Review of Applied Linguistics in Language Teaching, 41(4), 279-291.

Cruse, D. A. (2000). The lexicon. In M. Aronoff, \& J. Rees-Miller (Eds.), The handbook of linguistics (pp. 238-264). Oxford, England: Blackwell publishing.

Dörnyei, Z. (2005). The psychology of the language learner. Mahwah, NJ: Lawrence Erlbaum.

Graik, F. I. M., \& Lockhart, R. S. (1972). Levels of processing: A framework for memory research. Journal of Verbal Learning \& Verbal Behavior, 11, 671-684.

Greene, J. C. (2001). Mixing social inquiry methodologies. In V. Richardson (Ed.), Handbook of research on teaching (pp. 251-258). Washington DC: American Educational Research Association.

Gu, Y., \& Johnson, R. K. (1996). Vocabulary learning strategies and languages learning outcomes. Language Learning, 46(4), 643-679.

Hamouda, A. (2013). A study of dictionary use by Saudi EFL students at Qassim university. Study in English Language Teaching, 1(1), 228-257.

Heaton, J. (1988). Writing English language tests In J. Harmer, \& R. Kingsbury (Eds.), 


\section{I Macrothink}

International Journal of Linguistics

ISSN 1948-5425

2021, Vol. 13, No. 5

Longman handbooks for Language teachers ed. New York, The United States of America: Longman Inc.

Hedge, T. (2000). Teaching and learning in the language classroom. Oxford: Oxford University Press.

Heidri, F. L., Karimi, F., \& Imani, A. (2012). Vocabulary learning strategy instruction: Its impact on English for specific purpose vocabulary achievement and reading comprehension. Middle-East Journal of Scientific Research, 12(11), 1488-1496.

Hsu, C. (2007). Effects of the keyword method on vocabulary learning of elementary school EFL children. Unpublished Master Thesis ed.. Department of English Instruction, Taipei: Municipal University of Education.

Hulstijn, J. H. (1992). Retention of inferred and given word meanings: Experiments in. In P. J. Arnaud, \& H. Bejoint (Eds.), Vocabulary and applied linguistics (pp. 113-125). London: Macmillan.

Kafipour, R.,Yazdi, M., Soori, A., \& Shokrpour, N. (2011). Vocabulary Levels and Vocabulary learning strategies of Iranian Undergraduate students. Studies in Literature and Language, 3(3), 64-71.

Koizumi, R. (2005). Relationships between productive vocabulary knowledge and speaking performance of Japanese learners of English at the novice level. Unpublished doctoral dessertation. University of Tsukuba: Japan.

Lawson, M. J., \& Hogben, D. (1996). The vocabulary learning strategies of foreign language students. Language Learning, 46(1), 101-135.

Little, D. (1997). Strategies in language learning and teaching: Some introductory reflections. CILT Research Forum: Strategies in foreign language learning. London.

Llinares, G., Leiva, B., Cartaya, N., \& St. Louis, R. (2008, September). Acquistition of L2 vocabulary for effective reading: Testing teachers' classroom practice. The Reading Matrix, $8(2)$, 55-69.

Marefat, H., \& Shirazi, M. A. (2003, September). The impact of teaching direct learning strategies on the retention of vocabulary by EFL learners. The Reading Matrix, 3(2), 47-62.

Merriam, S. B. (1998). Case study research in education and psychology: A Qualitative approach. San Francisco: Jossey-Bass.

Mizumoto, A., \& Takeuchi, O. (2009). Examinning the effectiveness of explicit instruction of vocabulary learning strategies with Japanese EFL university students. Language Teaching Research, 13(4), 425-449.

Nation, I. S. (1997). Brining today's vocabulary research into tomorrow's classrooms. In G. Jacobs (Ed.), Language Classrooms of Tomorow: Issues and Responses RELC (pp. 170-182). Anthology Series No. 38. 


\section{MInstitute Macrothink $_{\text {Int }}$}

International Journal of Linguistics

ISSN 1948-5425

2021, Vol. 13, No. 5

Nation, P. (2001). Learning vocabulary in another language. Cambridge: Cambridge University Press.

Nemati, A. (2009). Memory vocabulary learning strategies and long-term retention. International Journal of Vocational and Technical Education, 1(2), 014-020.

Nemati, A. (2013). Vocabulary learning strategies: A short way to long term retention. Linguistics and Literature Studies, 1(1), 8-14.

Ningjue, Z. (2011). Learning how to Learn: A study of English vocabulary learning strategies among English major students at a Chinese university. Unpublished masters thesis, Kristianstad University, China.

Nunan, D. (1992). Research methods in language learning. Cambridge: Cambridge University Press.

Oxford, R. L., Crookall, D., Cohen, A., Lavin, R., Nylkos, M., \& Sutter, W. (1990). Strategy training for language learners: Six situational case studies and a training model. Foreign Language Annals, 22(3), 197-216.

Politzer, R. L. (1978). Errors in English speakers of German as perceived and evaluated by German natives. Modern Language journal, 62(4), 253-261.

Prabhu, N. (1987). Second language pedagogy. Oxford University Press.

Rasekh, Z. E., \& Ranjbary, R. (2003, September). Metacognitive strategy training for vocabulary. Teaching English as a Second or Foreign Language, 7(2), 1-21.

Rubin, D. (1987). Learner strategies: Theoretical assumptions, research, history. In A. Wenden, \& J. Rubin (Eds.), Learner Strategies in Language Learning (pp. 15-30). Eaglewood Cliffs, New Jersey: Prentice-Hall.

Rubin, J., Chamot, A. U., Harris, V., \& Anderson, N. J. (2007). Intervening on the use of strategies. In A. Cohen, \& E. Macaro (Eds.), Language Learner Strategies: 30 Years of Research and Practice (pp. 29-45). Oxford,U.K.: Oxford University Press.

Sanaoui, R. (1995). Adult learners' approach to learning vocabulary in second languages. The Modern Language Journal, 79(2), 15-28.

Sanchez, A., \& Manchon, R. M. (2007). Research on second language vocabulary acquisition and learning: An introduction. International Journal of English Studies, 7(2), vii-xvi.

Sardroud, S. (2013, May). Impact of training deep vocabulary learning strategies on vocabulary retention of Iranian EFL learners. International Journal of Applied Linguistics and English Literature, 2(3), 75-82.

Schmitt, N. (1997). Vocabulary learning strategies. In N. McCarthy, \& M. Schmitt (Eds.), Vocabulary: Description, Acquisition and Pedagogy (pp. 77-85). Cambridge: Cambridge University Press.

Smith, R. K. (1998). Building Vocabulary for College. Boston: Houghton Mifflin. 


\section{Al Macrothink}

International Journal of Linguistics

ISSN 1948-5425

2021, Vol. 13, No. 5

Sökmen, A. (1997). Current trends in teaching second language vocabulary. In M. McCarthy, \& N. Schmitt (Eds.), Vocabulary: Description, Acquisition and pedagogy (pp. 237-257). Cambridge: Cambridge University Press.

Tassana-ngam, I. (2005). The effect of vocabulary learning strategies training on Thai university students' word retention in the second language classroom. Unpublished PhD thesis, Department of Language and Linguistics, University of Essex.

Tavakoli, M., \& Gerami, E. (2013). The effect of the keyword and pictorial methods on EFL learners' vocabulary learning and retention. Porta Linguarm, 19, 299-316.

Zahedi, K. (2008). Metacognitive learning strategies and academic success of TEFL M.A. students in distance education. International Journal of Criminology and Sociological Theory, $1(2), 161-176$.

Zheng, L. (2010). Strategies in Vocabulary Learning and Teaching. Unpublished masters thesis, Kristianstad University College, China.

Zimmerman, C. B. (1997). Historical trends in second language vocabulary instruction. In J. Huckin, \& T. Coady (Eds.), Second Language Vocabulary Acquisition: A Rationale for Pedagogy (pp. 5-19). Cambridge: Cambridge University Press.

\section{Appendix}

\section{Appendix 1. Pre-Post Questionnaire}

A- How often do you use each of the following strategies to discover the meaning of a new word?

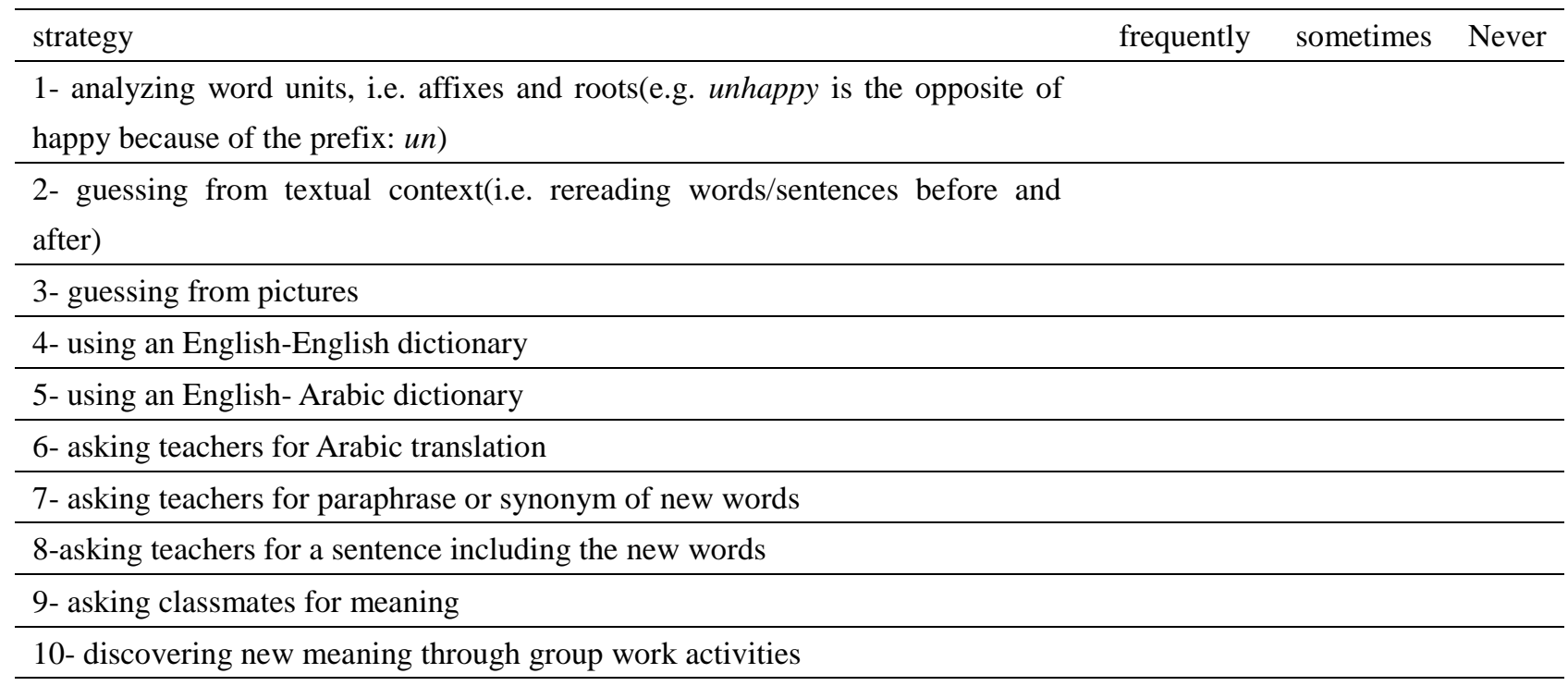




\section{Macrothink}

International Journal of Linguistics

ISSN 1948-5425

2021, Vol. 13, No. 5

B- How often do you use each of the following strategies to consolidate a word you have encountered earlier?

\begin{tabular}{|c|c|c|c|}
\hline strategy & frequently & sometimes & Never \\
\hline \multicolumn{4}{|l|}{ 11- verbal repetition(e.g. repeating the words many times aloud) } \\
\hline \multicolumn{4}{|l|}{ 12- written repetition (e.g. writing the words many times) } \\
\hline \multicolumn{4}{|l|}{$\begin{array}{l}\text { 13- taking notes(e.g. writing down the important information about a specific } \\
\text { word that you feel will help you remember it in the future) }\end{array}$} \\
\hline \multicolumn{4}{|l|}{$\begin{array}{l}\text { 14- putting English labels on physical objects(e.g. writing the name of your } \\
\text { stuff(papers, pencils, pens, shoes, socks ..etc) in your room in English) }\end{array}$} \\
\hline \multicolumn{4}{|l|}{$\begin{array}{l}\text { 15- studying word with a pictorial representation of its meaning(e.g. drawing an } \\
\text { eye next to the word sight) }\end{array}$} \\
\hline \multicolumn{4}{|l|}{$\begin{array}{l}\text { 16-imaging word's meaning(thinking of a street full of cars to remember the } \\
\text { meaning of crowd) }\end{array}$} \\
\hline \multicolumn{4}{|l|}{$\begin{array}{l}\text { 17- associating the word with its coordinates(e.g. associating Kiwi with grapes } \\
\text { and bananas because they are all types of fruit) }\end{array}$} \\
\hline \multicolumn{4}{|l|}{ 18- connecting the word to its synonyms and antonyms } \\
\hline \multicolumn{4}{|l|}{$\begin{array}{l}\text { 19-using semantic maps(i.e. writing the new word at the centre of a map(e.g. } \\
\text { season) with arrows forming the related words previously learned(e.g. summer, } \\
\text { sunny, picnic, ..etc) }\end{array}$} \\
\hline \multicolumn{4}{|l|}{$\begin{array}{l}\text { 20- using scales for gradable words (adjectives, adverbs, nouns, verbs) (e.g. } \\
\text { arranging the following adverbs: always-often-occasionally-seldom-never) }\end{array}$} \\
\hline \multicolumn{4}{|l|}{$\begin{array}{l}\text { 21- grouping words together to study them(studying the parts of the human } \\
\text { body together such as eyes-ears-mouth-face ..etc) }\end{array}$} \\
\hline \multicolumn{4}{|l|}{$\begin{array}{l}\text { 22- grouping words together spatially on a page(i.e. writing all the words that } \\
\text { may go together in one group such as } I \text {, he, she, it, me, him, her, mine, his, } \\
\text { hers ..etc) }\end{array}$} \\
\hline \multicolumn{4}{|l|}{ 23- using new words in sentences } \\
\hline \multicolumn{4}{|l|}{ 24- studying the spelling of words } \\
\hline \multicolumn{4}{|l|}{ 25- studying the pronunciation of words } \\
\hline \multicolumn{4}{|l|}{$\begin{array}{l}\text { 26- imaging word form(e.g. thinking of all the vowels in quiet as being between } \\
\text { consonants which could be linked to its meaning) }\end{array}$} \\
\hline \multicolumn{4}{|l|}{ 27- using keyword method(i.e. associating an Arabic/English word that sounds } \\
\hline \multicolumn{4}{|l|}{$\begin{array}{l}\text { that can help you remember it easily [imagining that A dictionary can help one } \\
\text { when preparing for a } \underline{\text { dictation test]) }}\end{array}$} \\
\hline \multicolumn{4}{|l|}{ 28- testing yourself with wordlists } \\
\hline \multicolumn{4}{|l|}{ 29- skipping or passing new words } \\
\hline \multicolumn{4}{|l|}{ 30- continuing to study words over time } \\
\hline \multicolumn{4}{|l|}{ 31- studying and practicing meaning in a group } \\
\hline 32- interacting with your classmates in English (e.g. chatting in English) & & & \\
\hline
\end{tabular}




\section{Macrothink}

International Journal of Linguistics

ISSN 1948-5425

2021, Vol. 13, No. 5

C- How often do you use each of the following strategies to improve your English vocabulary knowledge and/or learn new words on your own?

\begin{tabular}{|c|c|c|}
\hline strategy & sometimes & Never \\
\hline \multicolumn{3}{|l|}{ 33- studying words directly from a dictionary } \\
\hline \multicolumn{3}{|l|}{ 34-using a published word list } \\
\hline \multicolumn{3}{|l|}{$35-$ reading stories and novels } \\
\hline \multicolumn{3}{|l|}{ 36- reading newspapers and magazines } \\
\hline \multicolumn{3}{|l|}{ 37- listening to English radio programs } \\
\hline \multicolumn{3}{|l|}{ 38- watching English TV programs(movies, newscasts, documentaries) } \\
\hline \multicolumn{3}{|l|}{ 39- surfing the internet } \\
\hline \multicolumn{3}{|l|}{ 40- designing/ compiling your notebook for vocabulary items } \\
\hline \multicolumn{3}{|l|}{ 41- deciding the important words you need to learn } \\
\hline \multicolumn{3}{|l|}{ 42- evaluating your vocabulary knowledge } \\
\hline \multicolumn{3}{|l|}{ 43-planning revision for vocabulary } \\
\hline \multicolumn{3}{|l|}{ 44-discussing problems regarding vocabulary learning with a teacher } \\
\hline \multicolumn{3}{|l|}{ 45- discussing problems regarding vocabulary learning with classmates } \\
\hline \multicolumn{3}{|l|}{$\begin{array}{l}\text { 46-interacting with native speakers online (facebook, twitter, whatsapp, } \\
\text { forums...etc) }\end{array}$} \\
\hline \multicolumn{3}{|l|}{ 47- trying out new strategies for learning vocabulary } \\
\hline \multicolumn{3}{|l|}{ 48- using multiple strategies for vocabulary learning } \\
\hline 49-selecting the most appropriate vocabulary learning strategies & & \\
\hline
\end{tabular}

\section{Appendix 2. The Vocabulary Achievement Test}

Part 1: Circle the letter of the correct word. Note: there is only ONE correct answer for each item.

1- ........can be defined as someone who tries to harm other people.
a- Attacker
b-Volunteer
c-Master
d-Employer

2- To .....something over is to examine it for a short period of time.
a- watch
b- talk
c-hand
d- look

3- $\quad$.......is a soft, reddish- brown metal
a- Gold
b-Silver
c-Cooper
d- Lead

4- A ..........is someone who studies and analyzes language. a- linguist

b- biologist
c-psychologist
d-sociologist

5- .............are easily-recognized objects in a landscape such as a statue or building.
a- tracks
b-landmarks
c-terminals
d- apartments

6- To something means to begin or create it.
a- surround
b-permit
c-preserve
d- establish

7- A ......... is a very bad event or accident such as a plane crash.
a- ceremony
b- disaster
c-process
d-civilization 
8- An ..........is a building where sea animals are kept.
a- aquarium
b- anchor
c- ecosystem
d- ornament

9- A is $1,000,000,000,000$.
a- hundred
b- thousand
c-million
d- trillion

10- Although we come from the same family, we do not share most of our beliefs; his views with my own.
a- contrast
b- agree
c- compare
d-account

11- Many people have got this dangerous disease but the doctors still can't tell why; the causes are still........
a-familiar
b- unfamiliar
c- known
d- unknown

12- The man was found dead in his house but no one knows who ..him.
a- murdered
b-excluded
c-conducted
d- enabled

13- When my friend said that my story was unbelievable, she ... that I was lying.
a- interacted
b- crushed
c- invaded
d- implied

14- It was your own idea in the first place, so you can hardly ..now.
a- object
b- deduce
c- assume
d- understand

15- Some museums have several ........... of people and animals that can attract many tourists.
a- gulfs
b- caves
c-trees
d-

sculptures

16- Smoking ........people to the risk of lung cancer.
a-qualifies
b-energizes
c- exposes
d- distributes

17- When you........, you need special breathing equipment.
a- dive
b- walk
c- drown
d- run

18- The temperatures get extremely cold as you move towards the
a- tropics
b-poles
c- gulfs
d- channels

19- The opposite of accurate is .....
a- inaccurate
b-unaccuarate
c-nonaccurete
d-disaccurate

20- In winter, rivers and lakes in some parts of the world are
a-freezen
b- frozen
c- freezed
d-freeze

Part 2: Write the correct form of the words between the two brackets:

21- These fields have been under for a very long time. (cultivate)

22- Asma and her mother look similar. (remark)

23- Ali was to speak on behalf of the whole class. (select)

24- Children must be kept under supervision. (constantly)

25- You must .the sentence to find out where the error is. (analysis)

26- Rich people usually live a very life. (luxury)

27- The ......of the hotel is ideal; no one can miss it. (locate)

28- The United States of America is.......rich and diverse because many people from different parts of the 
world live there. (culture)

29- The fire completely .... ...the house. (destruction)

$30-\ldots \ldots \ldots . .$. is a process by which the vapor goes upward into the atmosphere where it cools and then forms the clouds. (condense)

\section{Appendix 3. The Interview Guide for the Experimental Group}

1- Of the six strategies you were trained in, which one did you select to help you remember the words you learn? If none, why not?

2- After being introduced to the six strategies, how do you rate your frequency to use them on a scale from 1 to 10 (with 10 being the highest)?

3- How did the strategies you frequently employ when learning vocabulary change after the training you received?

4- Did the training program help you try out new strategies for learning vocabulary? If yes, why? If no, why not?

5- How did the training program help you be selective in using strategies when leaning vocabulary?

6- How do you rate your motivation to plan revision for vocabulary on a scale from 1 to 10 (with 10 being the highest) after being introduced to the training program?

7- How did the training program contribute to improving your vocabulary learning?

8- In what way could the VLS training program be made more beneficial?

\section{Copyrights}

Copyright for this article is retained by the author(s), with first publication rights granted to the journal.

This is an open-access article distributed under the terms and conditions of the Creative Commons Attribution license (http://creativecommons.org/licenses/by/4.0/) 